Yohji Okada, Fumiya Kitayama and Ryou Kondo

\title{
Design of high-speed interior permanent magnet-type motor for turbo machinery
}

ABSTRACT. A high speed interior permanent magnet (IPM)-type motor is proposed. It is intended for application to high speed turbo-machinery supported by magnetic bearings. Such a system usually calls for a big uninterruptible power supply (UPS) to support the rotor when the power supply stops suddenly. The proposed motor generates electric power from the rotational energy when the power suddenly ceases. The regenerated energy is used to operate the magnetic bearing until the rotor speed slows down. The rotor touches down to the emergency ball bearing. This high speed IPM-type motor easily regenerates the electric energy with diodes only, which can replace the big UPS. This paper proposes a two-pole IPM motor as a generator for such a sudden power interruption. For high speed rotation, a two-pole IPM motor is fabricated and tested.

Keywords: high-speed motor, magnetic bearing, regenerative energy

Nanotechnology Perceptions 15 (2019) 227-237

doi: 10.4024/N25OK19A.ntp.15.03 